
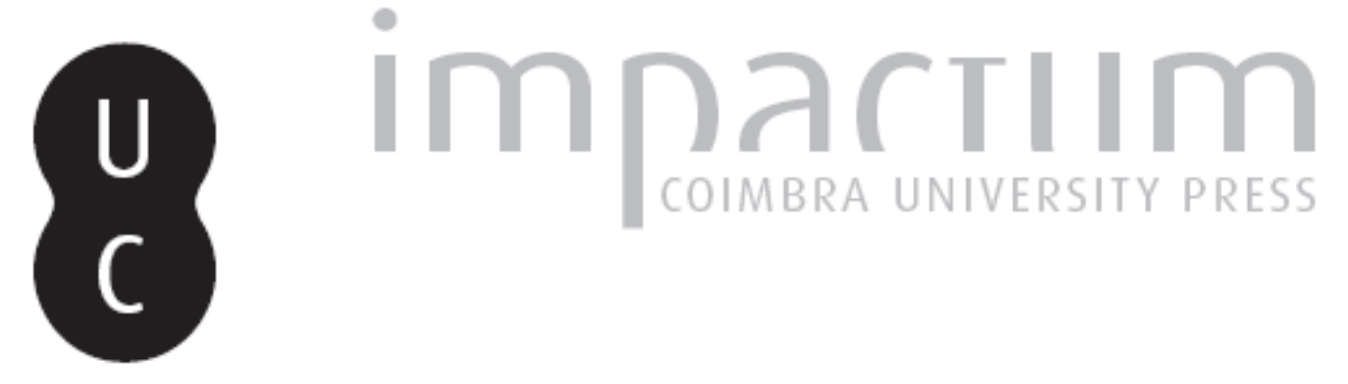

\title{
Elementos arquitectónicos de época romana da Casa dos Bicos - Lisboa
}

Autor(es): $\quad$ Fernandes, Lídia

Publicado por: Imprensa da Universidade de Coimbra

URL persistente:

URI:http://hdl.handle.net/10316.2/45391

DOI:

DOI:https://dx.doi.org/10.14195/1647-8657_38_6

Accessed : $\quad$ 26-Apr-2023 13:49:57

A navegação consulta e descarregamento dos títulos inseridos nas Bibliotecas Digitais UC Digitalis, UC Pombalina e UC Impactum, pressupõem a aceitação plena e sem reservas dos Termos e Condições de Uso destas Bibliotecas Digitais, disponíveis em https://digitalis.uc.pt/pt-pt/termos.

Conforme exposto nos referidos Termos e Condições de Uso, o descarregamento de títulos de acesso restrito requer uma licença válida de autorização devendo o utilizador aceder ao(s) documento(s) a partir de um endereço de IP da instituição detentora da supramencionada licença.

Ao utilizador é apenas permitido o descarregamento para uso pessoal, pelo que o emprego do(s) título(s) descarregado(s) para outro fim, designadamente comercial, carece de autorização do respetivo autor ou editor da obra.

Na medida em que todas as obras da UC Digitalis se encontram protegidas pelo Código do Direito de Autor e Direitos Conexos e demais legislação aplicável, toda a cópia, parcial ou total, deste documento, nos casos em que é legalmente admitida, deverá conter ou fazer-se acompanhar por este aviso.

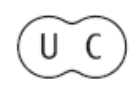


UNIVERSIDADE DE COIMBRA

FACULDADE DE LETRAS

\section{CONIMBRIGA}

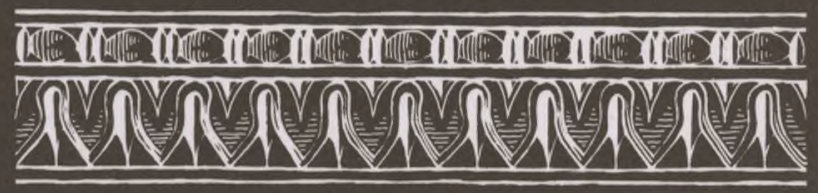

VOLUME XXXVIII - 1999 


\section{LÍDIA FERNANDES}

Mestre em História da Arte.

Arqueóloga da Divisão de Museus da C. M. L. - Museu da Cidade.

\section{ELEMENTOS ARQUITECTÓNICOS DE ÉPOCA ROMANA}

DA CASA DOS BICOS - LISBOA

"Conimbriga" XXXVIII (1999) p. 113-135

REsumo: Estudam-se alguns elementos arquitectónicos exumados da Casa dos Bicos durante a escavação de 1993.

A análise estilística e a integração arquitectónica possibilitaram informações acerca da cronologia, das oficinas e de aspectos técnicos e artísticos que se põem em paralelo com o que se conhece da Lisboa romana.

ABSTRACT: Various architectural elements from the Casa dos Bicos in Lisbon are described. They were found in 1993 during excavations undertaken by I.P.P.A.R. (Archaeological Institute of Portugal).

The author presents a comparative study in an attempt to find information concerning chronologies, workshops and technical and artistic aspects. This is done through stylistic analysis and investigation of the architectural integration of these relies of Roman Olisipo. 
(Página deixada propositadamente em branco) 


\section{ELEMENTOS ARQUITECTÓNICOS DE ÉPOCA ROMANA DA CASA DOS BICOS - LISBOA ${ }^{1}$}

\section{INTRODUÇÃO}

A intervenção arqueológica realizada na Casa dos Bicos em 1982 permitiu colocar a descoberto uma parte importante da historia de Lisboa no que concerne ás épocas romana, medieval e moderna. As peças que apresentamos, correspondentes exclusivamente ao primeiro período, foram já, algumas delas, objecto de referências em várias publicações, ainda que nenhuma tenha suscitado uma análise pormenorizada ${ }^{12}$.

Encontram-se depositadas no Museu da Cidade - Câmara Municipal de Lisboa - figurando, actualmente, na sua exposição permanente (Sala Romana III). Algumas não permitem, pela dimensão ou pela ausência de características identificadoras que ostentam, considerações

1 Gostaríamos de agradecer ao Professor Doutor José d'Encarnação, que releu o presente artigo fazendo os comentários apropriados à sua redaç̧ão; ao Dr. Eurico Sepúlveda que teve a amabilidade de traduzir o resumo; ao Dr. dementino Amaro, coordenador da escavação da Casa dos Bicos, que nos prestou os esclarecimentos necessários no que concerne ao achado dos materiais. E, acima de tudo, ao Professor J. M. Bairrão Oleira, pelo incondicional apoio e permanente incentivo aquando da preparação da tese de mestrado, de que este trabalho foi parte integrante.

2 Como, por exemplo, em MoITA, Irisalva, "Das origens pré-históricas ao domínio romano", Livro de Lisboa, Livros Horizonte, Lisboa, 1994, pp. 42-60, onde a autora faz referência ao capitel e ao capeamento de ara; SANTos, Vítor Pavão dos, Catálogo - A Casa dos Bicos e a Lisboa Ribeirinha, Os Descobrimentos Portugueses e a Europa do Renascimento - a Dinastia de Avis -, Núcleo da Casa dos Bicos, XVII Exposição Europeia de Arte, Ciência e Cultura, Casa da Moeda, Lisboa, 1983, p. 260, concretamente . $^{\circ} 335$ - capitel; n. 336 - base de coluna; n. 339 - capeamento de ara, aqui, os materiais somente têm entrada de catálogo. Augusto, José Manuel Lopes, Casa dos Bicos, o Espelho da História de Uma Cidade, Comissão Nacional para as Comemorações dos Descobrimentos Portugueses, Printer Portuguesa, s/1, 1996, p. 26. 
de ordem cronológica e/ou estilística, como é o caso do lintel de porta ${ }^{3}$ ou alguns frisos; outras há, porém, como o capeamento de ara ou o capitel, cujos pormenores decorativos e apurada técnica executiva evidenciada justificam, à partida, uma abordagem mais pormenorizada ${ }^{4}$.

$\mathrm{O}$ estudo que a seguir elaboramos pretende ser uma análise detalhada destes elementos arquitectónicos. Este estudo inicia-se por análises descritivas dos diversos materiais avançando-se, posteriormente, para paralelos comparativos que permitam inferir cronologias, influências e oficinas de produção.

1 - CAPITEL (Figs. 1 e 2)

N. ${ }^{\circ}$ Inv. - 496 (Inv. Geral: 5486)

\section{Descrição}

Matéria - lioz

Técnica - utilização de escopro de ponta e de bisel nos pormenores decorativos. Uso pontual do trépano. Abrasivos de polimento na superfície. Zonas laterais de encaixe denotam uso de escopro de ponta, bem como de trépano, ainda que realizado em áreas circunscritas. Nervuras feitas com escopro de bisel e outras, superficiais, realizadas com punção de bico.

Dimensões (em $\mathrm{cm}$ ) - altura total: 39 ; comprimento total: 42; profundidade da base: 20; altura do ábaco: 7; altura da Ia coroa de folhas: 15; altura da $2^{\text {a }}$ coroa de folhas: 14 .

Estado de conservação - Bom. Partido no ábaco.

\section{Análise descritiva}

Capitel de coluna de adossamento. A decoração divide-se em dois andares ocupando o superior a maior parte da peça. A vegetalização das tradicionais volutas, a par com outras características, são

3 Apesar de se constituir como um importante elemento arquitectónico, as suas características morfológicas, técnicas e decorativas não nos permitem grandes considerações.

4 Agradecemos ao Dr. dementino Amaro a autorização concedida para o estudo destes materiais. 
os factores fundamentais a integrar esta peça na classificação de "capitel corintizante".

O registo inferior apresenta três folhas completas e duas meias-folhas, localizadas estas nos extremos do capitel. As folhas acantizantes articulam-se em três lóbulos de cada lado da nervura central, sendo a separação entre os mesmos sublinhada pelo uso pontual do trépano, cuja concavidade contrasta com o pouco ressalto lobular. A parte superior das folhas desgarra-se do kalathos $^{5}$ afirmando um ângulo acentuado.

$O$ andar superior apresenta três elementos foliáceos: um, central, ocupando praticamente toda a face do capitel, e dois a formar ângulo, de idênticas características às da imma folia ${ }^{6}$.

Os extremos do capitel, no registo vegetalista superior, apresentam, junto à face vertical da peça, um motivo constituído por elementos verticais, de altura progressivamente maior e com terminações circulares (Fig. 2). Junto à base destes e ocupando o espaço livre entre os mesmos e a folha angular adjacente, observa-se uma pequena roseta quadripétala com botão central liso e relevado.

Um motivo em ziguezague formando, através dos seus ângulos cerrados, pequenos triângulos emoldurados, situa-se por cima das folhas da imma folia, concretamente, da folha central inferior e por cima de duas meias folhas laterais do mesmo registo, como que formando uma pequena coroa radial.

O ábaco encontra-se partido, notando-se, no entanto, a sua original molduração bem como o local onde se situaria a tradicional flor do ábaco, ainda que não conservada.

\section{Análise comparativa}

Esta peça, encontrada em 1983 7, é um capitel de adossamento que mantém, na face posterior, parte do bloco a encaixar na parede do edifício.

${ }^{5}$ Kalathos corresponde ao cesto ou corpo da peça, excluindo o ábaco.

${ }^{6}$ Atribui-se a designação de imma e summa folia, respectivamente, à coroa inferior e superior de folhas que se desenvolvem a toda a volta da peça.

${ }^{7}$ Nas escavações arqueológicas então realizadas na Casa dos Bicos, tendo sido incorporada no Museu da Cidade em Fevereiro de 1984.

Conimbriga, 38 (1999) 113-135 
É composta por duas coroas de folhas de estilo corintizante com três lóbulos de cada lado da nervura central. As terminações lobulares são curiosas, uma vez que apresentam uma meia-lua incisa a representar o reviramento do lóbulo. Ainda que procurando obter um efeito naturalista com este pormenor, o resultado final é rígido e a representação acentuadamente esquemática. Aspecto idêntico podemos observar numa peça de Córdova ${ }^{8}$, datada da época de Adriano.

Os lóbulos apresentam uma pequena nervura relevada, a marcar o seu centro, provocando uma ligeira concavidade nas duas metades lobulares, adoptando uma forma que Patrizio Pensabene definiu como "lóbulos bilobados" 9 e cuja morfologia pode ser facilmente observada em Ostia em peças datadas da primeira metade do séc. $\mathrm{II}^{10}{ }^{11}$. Nervuras relevadas em lóbulos semelhantes podem ser observadas em peças cordovezas, também da época de Adriano ${ }^{11}$.

As folhas apresentam um formato rectangular e aderem ao kalathos com excepção da sua parte superior onde descrevem um recurvamento acentuado para o exterior. Nesse local e na face externa de cada uma das folhas não é visível qualquer acabamento, indicando uma ausência de abrasivos de afeiçoamento ${ }^{12}$.

Os lóbulos são justapostos e as uniões interlobulares apresentam um ponto de trépano bem marcado e profundo, que se prolonga pela incisão da divisão lobular através de duplo talhe em bisel. $O$ efeito é muito regular e as características do talhe suscitam, apesar da quase total ausência de volumes, alguns efeitos de luz e sombra.

$\mathrm{O}$ uso pontual do trépano, tal como encontramos neste exemplar, pode ser observado em alguns capitéis de Roma com uma cronologia que aponta para os finais do séc. I e a primeira metade do séc. II ${ }^{13}$. Em comparação, a peça da Casa dos Bicos indica-nos uma realização

8 Carlos Marquez, Capiteles Romanos de Corduba Colonia Patricia, Córdoba, 1993, pp. 127 e 128, n. $^{\circ} 238$.

9 Pensabene, Patrizio, Scavi di Ostia - I Capitelli, VII, Roma, 1973, p. 218.

10 Pensabene, ob. cit., peças n. ${ }^{\text {os }} 559,560,573$ e 590.

11 Carlos Marquez, ob. cit., p. 125, n. ${ }^{\circ} 233$; p. 127, n. ${ }^{\circ} 236$; p. 128, n. $^{\circ} 240$; pp. 135 e 136, n. $^{\circ} 255$.

12 Característica que geralmente se observa, uma vez que esta zona da peça não seria visível. Evitavam-se, deste modo, trabalhos de acabamento supérfluos.

13 LuPI, Loretta; Gallottini, Angela, Museo Nazionale Romano - Le Sculture, I, 11., Itália, 1991, pp. 38 e 39, n.os 63 e 64. 
menos cuidada, sendo os vários componentes ornamentais mais grosseiros.

A nervura central, que abrange toda a altura do elemento foliáceo, quer na primeira quer na segunda coroa de folhas, apresenta-se ligeiramente mais larga na parte inferior, descrevendo, assim, uma curvatura pouco acentuada. E ladeada por alguns sulcos paralelos não contínuos. Esta representação faz aproximar estas folhas das dos capitéis corintios, tal como elas passam a ser representadas a partir do séc. $\mathrm{II}^{14}$, ainda que os sulcos sejam aqui bastante mais marcados. A tendência, no entanto, é a da perda dos grandes efeitos de sombra e luz, como podemos ver neste exemplar, alterando uma tradição de época flávia, caracterizada pela alternância de volumes bem como pelo intenso uso do trépano.

Não se verifica, pois, um contraste acentuado de relevos. As folhas aderem de forma perfeita ao corpo da peça e o respectivo recurvamento superior é bem marcado, o que se denota, pelo menos, nas folhas da imma folia, uma vez que não nos é possível observar a projecção que certamente teriam as da coroa superior ${ }^{15}$. Este tratamento da superfície do exemplar pode ser observado em peças de época Flávia, altura a partir da qual se perde, como já referimos, “... così in parte il senso dello spessore - bidimensionalità della foglia, non più tridimensionalità" 16 .

As características apontadas para as folhas da imma folia repetem-se nas duas folhas angulares superiores. Nestas, a nervura central é mais marcada, assim como mais relevada, com o objectivo de estabelecer uma acentuação angular do bloco pétreo.

A substituição das volutas tradicionais do capitel corintio por folhas ou, se quisermos, o processo de vegetalização destes elementos, observa-se a partir dos finais do séc. I, sendo um dos elementos definidores do capitel corintizante. Neste, o espaço entre as volutas da summa folia é, na maior parte dos casos, decorada por um léxico ornamental mais ou menos habitual. No capitel da Casa dos Bicos o espaço do kalathos entre folhas angulares encontra-se preenchido igualmente por

14 Vide Pensabene, ob. cit., p. 225 e ss.

15 Os dois ângulos da peça encontram-se partidos, bem como a zona correspondente ao ábaco. Deste modo, não nos é possível observar nem o recurvamento superior das folhas da summa folia que, neste exemplar, substituiriam as tradicionais volutas do capitel corintio, nem a flor que decoraria a face central do ábaco.

16 Pensabene, ob. cit., p. 217. 
uma folha, muito semelhante às anteriormente descritas, no entanto, aqui a explanação dos motivos é maior e os lóbulos descrevem uma curvatura mais ondeada. De facto, se, nas inferiores, os lóbulos se dispõem obliquamente e orientados para cima, aqui descrevem uma curva, inclinando-se inferiormente. As terminações lobulares são em forma de U, sublinhadas, mais uma vez, pela pequena incisão de idêntica morfologia. A coincidência dos lóbulos desta folha central e as das folhas angulares não é perfeitamente conseguida, facto visível, essencialmente, num dos lados da mesma, o que nos pode indicar, seguramente, a utilização de cartões quanto a cópia de modelos.

A temática decorativa das faces centrais dos capitéis corintizantes é relativamente habitual ${ }^{17}$, como podemos observar em peças provenientes de Córdova ou de Mérida, todas elas da segunda centúria18.

No exemplar agora em análise foi, no entanto, escolhida uma folha morfologicamente idêntica às que decoram a restante superfície da peça, o que, para além de pouco habitual, confere à composição um aspecto monótono e uma ausência de alternância de motivos. Essa repetição é quebrada por um cordão em ziguezague, relevado, situado por cima da folha central da imma folia. Este elemento depara-se-nos invulgar no léxico ornamental destas peças, ainda que não nos possamos esquecer que o capitel corintizante permite uma liberdade decorativa muito maior que a observada em relação aos seus congéneres corintios.

Desconhecemos exemplares em que tal motivo assim se apresenta, quer quanto à forma, quer no que diz respeito ao local onde se encontra representado. Duas peças, no entanto, oferecem composições passiveis de aproximação.

Uma, de Villa de Prado (Valladolid), é um capitel corintizante de folhas lisas, apresentando no centro das faces duas pequenas hastes de volutas apostas, em posição quase horizontal, e encimadas por um cordão em ziguezague. A peça foi datada dos secs. III/IV, de acordo com a cronologia da estrutura basilical onde foi encontrada19. Apesar

17 Quando é uma folha que ocupa esse espaço, emprega-se geralmente uma palmeta, tal como podemos observar num exemplar corintizante datado do séc. IV e proveniente de Itálica, ainda que, neste caso concreto, toda a composição seja muito estilizada.

18 G. BEHEMERID, ob. cit., pp. 195 e 196, n. ${ }^{\text {os }} 851-854$.

19 Observámos o exemplar quando nos deslocámos ao Museu Arqueológico de Valladolid (Sala VIII). As publicações sobre esta estação não a citam Exceptua-se o guia didáctico do Museu: Rodríguez-Aragón, Fernando Pérez, Guía Didáctica - Museo de Valladolid - Romanización y Mundo Visigodo, Valladolid, 1995, p. 15 
de o motivo se poder aproximar, toda a estrutura do exemplar aponta para épocas posteriores à cronologia que pensamos poder atribuir ao capitel da Casa dos Bicos, alterações relacionadas com uma simplificação e acentuada esquematização dos motivos decorativos.

O outro exemplar, também proveniente de um edifício basilical, desta vez da Villa de Materno (Toledo), é um capitel corintio: o cordão em ziguezague, também relevado, encontra-se localizado por baixo do ábaco, descrevendo uma curva no centro da peça (por baixo da flor do ábaco) e passando por cima da folha central da summa folia. Esta peça foi datada dos finais do séc. $\mathrm{IV}^{20}$.

Ainda que não possamos inferir, pelos últimos paralelos apontados, que também a presente peça seja de época tardia, é curioso verificar que os paralelos mais próximos se referem precisamente a cronologias posteriores àquelas que, pensamos, dever atribuir-lhe, aspecto que se nos afigura tanto mais estranho quanto o motivo do ziguezague irá ser largamente utilizado em época visigoda, ainda que na sua versão mais estilizada ${ }^{21}$. Este aspecto vem confirmar a dificuldade de atribuição cronológica apenas com base em alguns pormenores decorativos, assim como prova a utilização de alguns deles em épocas diversas, sem que se possam atribuir, de forma clara, a modismos ou correntes estilísticas específicas.

Este motivo do ziguezague repete-se, igualmente, por cima das duas meias-folhas que finalizam lateralmente a peça. Por cima destas, surge-nos um outro motivo, desta vez três pequenas hastes que se elevam superiormente e de forma crescente 22 até terminarem, recurvándole ligeiramente para a face do capitel, em três círculos. Situa-se na parte inferior desta composição uma pequena roseta quadripétala com botão central relevado.

(e figura da mesma página). O desenho apresentado não nos parece, no entanto, muito fidedigno em relação à representação dos vários motivos. Sobre esta estação arqueológica, vide igualmente: ESCUDERO NAVARRo, Zoa, et alii, Arqueología Urbana en Valladolid, Museo Arqueológico de Valladolid, Valladolid, 1991, pp. 13-16. GUTIERREZ BEHEMERID, ob. cit, 1992, também não refere este exemplar.

20 Pilar Lanuza; San Augustîn, "La Villa de Materno", Revista de Arqueologia, Ano XIII, n. ${ }^{\circ}$ 139, Zugarto Ediciones, Madrid, 1992, pp. $42-53$ (vide fig. p. 48).

${ }^{21}$ Cf. Cruz Villalón, Maria, Mérida Visigoda - la Escultura Arquitectónica y Litúrgica, Badajoz, 1985.

22 A primeira, mais perto da folha angular, apresenta uma altura mais pequena que a que se lhe segue, a qual, por sua vez, é menor que a seguinte. 
Desconhecemos paralelos exactos para este ornamento; contudo, ele inscreve-se na temática vegetalista que decorava, habitualmente, este tipo de peças, talvez por influência das hastes do "motivo liriforme" ou da lineariedade do motivo em "duplo S" que ocorre em capitéis corintizantes. A composição simples que observamos nestas duas meias-faces do capitel de Lisboa oferece-nos uma solução singular, certamente não arreigada a modelos pré-estabelecidos, ainda que influenciada por eles, o que denotará, a par com os motivos em ziguezague, uma liberdade decorativa e uma capacidade adaptativa original.

A comparação com exemplares, também corintizantes, da zona mais ocidental da Lusitânia, como é o caso de Santarém e de Alcácer do Sal, permite-nos observar pormenores ornamentais que se podem aproximar, concretamente no que se refere à terminação circular das hastes. Tais espécimes possibilitam-nos a definição morfológica do presente motivo dada a perfeita explanação e definição que ostentam. E possível, assim, definir uma meia-palmeta estilizada, como pode ser observada em peças desses locais datadas, na sua globalidade, do séc. II.

$\mathrm{O}$ facto de este exemplar ter aparecido na Casa dos Bicos, local cujo espólio aponta para uma datação de entre o séc. I a.C e o séc. IV $^{23}$, não nos auxilia quanto a uma determinação cronológica mais precisa. No entanto, os vestígios arquitectónicos encontrados - concretamente o capeamento de ara do qual falaremos em seguida - podem fornecermos informações cronológicas complementares.

$\mathrm{O}$ aspecto da peça é cuidado e o trabalho técnico sabiamente executado. Assim, pelas considerações expostas, datamos este exemplar do séc. II, inclinando-nos mais para a primeira metade ou meados da centúria do que para os finais da mesma ${ }^{24}$.

23 Para além de textos mais ou menos generalistas, ainda que importantes, faltam, como é sabido, trabalhos de pormenor sobre o espólio arqueológico exumado na Casa dos Bicos. Apesar de a bibliografia sobre este local não ser muito extensa, somente apontamos alguns trabalhos: AMARO, dementino, "Casa dos Bicos. Notícia Histórico-Arqueológica “, Arqueologia, n. ${ }^{\circ}$ 6, ed. G.E.A.P., Porto, 1982, pp. 96-111; Amaro, "Casa dos Bicos: sítio com dois milénios de História", Lisboa Subterrânea - Catálogo, ed. Electa, Lisboa, 1994, pp. 110-111.

24 A peça esteve em exibição na XVII Exposição Europeia de Arte, Ciência e Cultura, integrando o catálogo correspondente, aí, no entanto, não existe especificação da sua cronologia, já que somente se refere que se tratam de peças de época romana: SANTOS, ob. cit., n. ${ }^{\circ} 335$. 
2 - CAPEAMENTO DE ARA (Figs. 3 a 5)

N. ${ }^{\circ}$ Inv. - 497 (Inv. Geral: 5487)

\section{Descrição}

\section{Matéria - calcário}

Técnica - utilização de escopro de ponta em bisel nos pormenores decorativos, bem como escopro de ponta, especialmente reconhecível nas rosetas do fastigium. Vestígios de abrasivos de afeiçoamento, essencialmente na parte superior, com indícios do emprego de gradim fino. Emprego pontual do trépano.

Dimensões (em $\mathrm{cm})$ - altura total da parte frontal: 38; largura: 74; altura ào fastigium: 17,5; altura da base: 18 .

Estado de conservação - Muito bom. Uma das rosetas laterais encontra-se partida, assim como a parte superior da palmeta frontal.

\section{Análise descritiva}

Peça completa de capeamento superior de $\operatorname{ara}^{25}$. A decoração divide-se em dois registos distintos. O inferior é constituído por faixa de motivos vegetalistas de carácter estilizado, preenchida por motivos sinuosos repetitivos em forma de $U$ fechado. Este registo separa-se do superior por duas pequenas molduras. Superiormente, duas volutas laterais encimam a peça, com canal de voluta côncavo, pouco acentuado e com roseta central trilobada.

25 Aplicamos o termo "capeamento de ara", ainda que outras designações sejam empregues por vários autores. Num artigo relativo a uma peça semelhante, aplicámos então o termo "capitel de ara", FERNANDES, Lídia, "Sobre um capitel de ara do Palácio Fronteira", Miscellanea em Homenagem ao Professor Bairrão Oleiro, Ed. Colibri, Lisboa, 1996, pp. 179-187. Tal designação parte do facto de nos encontrarmos perante peças que, apesar de, originalmente, terem desempenhado uma função em conjunto com a ara ou cipo que as suportaria, se nos apresentam hoje como totalmente independentes. A sua decoração, semelhante em muitos aspectos à que observamos em capitéis - corintios ou jónicos - vale por si, sendo pertinente uma análise do ponto de vista estilístico, separada do suporte original.

Outras designações são utilizadas, tais como "lápide tumular", "placa de altar" ou "fragmento de composição de altar", cf. GAMER, G., "Formen Römischer Altäre auf der Hispanischen Halbinsel", Madrider Beiträge, 12 Mainz, 1989, respectivamente p. 229 - ES. 16; ES. 21 e ES. 23. Quanto a outras designações, vide FERNANDES, ob. cit., p. 181, n. 5. 
Outras duas rosetas, de maiores dimensões, ladeiam, no centro, um florão do tipo palmeta. Este apresenta sulcos, estrangulados a meio e unidos no centro por uma banda transversal ligeiramente relevada. Aquelas rosetas apresentam quatro lóbulos, cada um com nervura central e denunciando uso do trépano a representar o revirar do lóbulo, procurando-se, deste modo, evidente efeito naturalista, ainda que de forma esquematizada.

O puluinus 26 está decorado por folhas de água estilizadas, dispostas longitudinalmente e unidas, no centro, por um fuso consubstanciado por moldura (perpendicular ao toro) e ladeada por sulcos.

Superior e internamente, pode observar-se neste exemplar, bem como em praticamente todas as peças exentas desta tipologia, uma concavidade rudemente desbastada correspondente ao focus da peça.

\section{Análise comparativa}

Descontextualizado de qualquer memória histórica, a análise passível de ser realizada deste exemplar constitui, como a efectuada quanto ao capitel anteriormente descrito, um simples estudo estilístico comparativo. Se, em relação aos capitéis, esse estudo se nos depara difícil, uma vez que, a maior parte das vezes, assistimos a uma reelaboração local dos motivos então em voga, quanto aos capeamentos de ara essa dificuldade depara-se-nos muito mais complexa, uma vez que são muito poucos os exemplares documentados até agora, quer no que se refere às províncias da Hispania, quer quanto ao restante Império ${ }^{27}$.

A inexistência de materiais em quantidade suficiente que possibilitem uma calibração das informações obtidas através da análise estilística, leva-nos a recorrer a outros materiais, que não exclusivamente os capeamentos de ara, onde a ornamentação ou os particularismos

26 Faces laterais do capeamento situadas no registo superior do mesmo, isto é, não abrangendo a parte inferior correspondente à base. Pode igualmente ser empregue o termo português balaústre ao invés da designação latina a qual significa, em sentido restrito ou literal, coxim ou almofada.

27 Variadíssimos exemplos poderão ser referenciados. A maior parte deles, não obstante, corresponde a blocos monolíticos onde não existe separação entre o verdadeiro "capeamento de ara" ou, neste caso, o capitel, e o bloco inferior, sendo o paradigma fornecido pela Ara Pacis Augustae.

Conimbriga, 38 (1999) 113-135 
da decoração sejam passíveis de um estudo paralelo. Os capitéis são, quanto a este aspecto, que não o formal, um precioso auxiliar.

A decoração desta peça organiza-se em dois registos distintos (Fig. 3). A zona superior - correspondente ao fastigium - apresenta uma ornamentação que contrasta, pela sua qualidade técnica e regularidade do talhe, com a que observamos na parte inferior, a qual se nos depara muito mais esquemática, ainda que tal facto se prenda, directamente, com o tipo de motivos aí empregues.

A parte superior possui duas rosetas centrais, que concentram em si toda a importância decorativa desta parte da peça. São de grandes dimensões e apresentam um tratamento dos lóbulos revelador de um extremo cuidado executivo, traduzido aqui num delinear dos pormenores - com recurso ao talhe em bisel - que busca uma alternância de volumes e um efeito óptico acentuado (Fig. 4).

Rosetas semelhantes, especialmente no que se refere ao uso pontual do trépano - à volta do botão central relevado e nas terminações dos lóbulos - encontramo-las em variadíssimos capitéis, essencialmente corintizantes, por todo o Império. Bastará citar algumas peças provenientes de Ostia, datadas de entre os finais do séc. I e os últimos decénios do séc. II ${ }^{28}$; outra de Mérida, com uma cronologia da época de Adriano 29; um outro capitel conservado no Museu Nacional de Roma, da época de Trajano; ou um outro, do período de Adriano, também do mesmo museu ${ }^{30}$.

Várias outras peças se podem colocar em paralelo. O elemento mais importante corresponde ao facto de este tipo de rosetas, com marcação de pontos circulares nos locais referidos, se registar, quase exclusivamente, a partir dos inícios do séc. II. Em boa verdade, poderão encontrar-se outros exemplares com idêntica particularidade, atribuíveis a uma cronologia mais tardia, ainda que, quanto a estes, a restante decoração da roseta assim como as alterações morfológicas de outros motivos apontem para épocas posteriores. Neste caso concreto, observamos que, a par do emprego do trépano, os lóbulos são igualmente

28 Pensabene, ob. cit., p. 140 - n. ${ }^{\text {os }} 564$ e 565 e p. 141 - n. ${ }^{\circ}$ 568. O primeiro exemplar datado do séc. II; o segundo, de entre os finais do séc. I e os primeiros decénios da centúria seguinte; e o último datável dos últimos decénios do séc. II.

29 Barrera Anton, José Luis de la, Los Capiteles Romanos de Merida, Monografias Emeritenses - 2, Badajoz, 1984, p. 48, n. ${ }^{\circ} 64$.

30 GallotTini, ob. cit., pp. 71 e 72 , n. ${ }^{\text {os }} 71$ e 72 , respectivamente. 
decorados com nervura central relevada, talhada em bisel, o que produz um efeito demasiado elaborado e rebuscado, quase poderíamos chamar-Ihe, um certo "barroquismo" decorativo que afasta este exemplar, de modo claro, das formas desenhadas, depuradas e lineares tícas da época de Augusto ou mesmo dos inícios da época júlio-cláudia.

Esta alteração plástica, directamente relacionada com uma modificação do conceito estético, é perfeitamente visível também em relação aos capitéis. A proximidade decorativa entre alguns daqueles motivos e os que presenciamos neste capeamento, permite, a nosso ver, a pertinência dos paralelismos acima estabelecidos.

As duas rosetas dispõem-se de um e do outro lado do motivo central do fastigium, traduzido aqui por uma palmeta na derivação quase directa dos acrotérios que encontramos comummente na decoração de época grega $^{31}$. Seguindo essa tradição, estas palmetas apresentam-se, no mundo romano alto-imperial, muito mais estilizadas e assumindo aspecto mais rígido. Ainda que não se conserve a terminação superior da palmeta do capeamento da Casa dos Bicos, certamente que poderíamos aproximar este motivo dos que encontramos em outros tipos de decorações, como se pode observar num relevo da época de Cláudio ${ }^{32}$, ou em placas ornamentais de terracota provenientes de Roma, da época de Augusto $^{33}$, constituindo-se, assim, como um elemento largamente utilizado na decoração de época romana, ainda que alterando progressivamente a sua morfologia, bem como técnica de execução.

As rosetas laterais são muito mais contidas, contrastando com as duas do centro. Restringem a sua morfologia a três lóbulos largos com botão central também relevado, ladeado este, no seu perímetro, por três pontos de trépano.

Os canais das volutas são ligeiramente côncavos, o rebordo exterior relevado, criando uma espécie de pequeno filete, característica que encontramos nas volutas angulares dos capitéis corintios e jónicos a partir da época de Augusto ${ }^{34}$.

Este registo superior do capeamento separa-se do inferior - a base - por duas molduras. A primeira corresponde ao filete que delimita os

31 Sobre a origem dos acrotérios, vide FERNANDES, ob. eit., pp. 182 e 183.

32 KLEINER, Diana E.E., Roman Sculpture, Yale Publications in the History of Art, Yale University Press, London, 1992, p. 146, fig. n. ${ }^{\circ} 121$, datado de entre 45-50.

33 Garcia y Bellido, A., Arte Romano, Madrid, 1990, p. 215, figs. 310-313.

34 Pensabene, ob. eit., p. 209. 
canais das volutas. A inferior apresenta um perfil convexo, constituindo-se como a terminação superior do registo inferior.

A base é decorada por motivos encadeados, ligados entre si e assumindo uma morfologia curvilínea. Tais elementos deparam-se-nos como invulgares no léxico decorativo romano, ainda que pensemos estar em presença da estilização de um motivo comum do mundo grego, que irá ser reelaborado e recuperado na época romana trata-se do kyma ou moldura lésbia.

Este ornamento, geralmente utilizado em frisos, surge-nos a decorar elementos arquitectónicos vários, tal como podemos ver em capitéis compósitos provenientes de Saintes e datados de época flaviana ${ }^{35}$. Aqui, já a moldura lésbia nos aparece modificada adquirindo os seus diversos elementos um aspecto mais estilizado e grosseiro e sendo o relevo mais largo. Deixando as províncias, também Roma nos oferece motivos similares, tal como podemos observar nos frisos da basílica Ulpia do forum de Trajano ${ }^{36}$. Também aqui, apesar do elegante traçado e da primorosa execução técnica evidenciada pelo delicado delinear da composição, os elementos nos surgem já modificados, devido ao respectivo alargamento e simplificação do relevo.

Se visualizarmos este friso em posição inversa, observaremos uma singular similitude com a composição que nos é dada pelo capeamento de ara da Casa dos Bicos, ainda que essa simplificação seja aqui levada ao extremo e a regularidade dos elementos que compõem o kyma lésbio afastem a composição da sua organicidade original.

Nos ângulos do registo inferior ainda é possível notar, apesar do desgaste da superfície, meias-folhas do tipo palmeta, estilizadas e com terminações dos lóbulos acentuados por pontos de trépano.

As faces laterais do registo superior - correspondentes aos pul$u_{i n i^{37}}$ - surgem-nos decoradas como se de um capitel jónico se tratasse, seguindo, de igual forma, a decoração habitual para este tipo de peças (Fig. 5). Os motivos assemelham-se a folhas de água muito esti-

35 TARDY, Dominique, "Le décor architectonique de Saintes antique", Aquitania Supplément 5, Ed. C.N.R.S., Paris, 1989, pp. 90-96, $n^{\text {TM } 49.87, ~ 49.100 . ~}$

36 KLEINER, ob. cit., p. 215, fig. 178.

37 Utilizamos aqui a terminologia dos capitéis jónicos canónicos, ou seja, com faces iguais duas a duas, nomenclatura que empregamos como alternativa ao termo português de "balaústre". Ao estrangulamento central desta parte da peça aplicamos o termo "fuso" que, em latim, se designa por balteus. 
lizadas, correspondendo a um dos motivos ornamentais que conta com mais exemplares no mundo romano ${ }^{38}$. Quanto às províncias mais ocidentais, esta escolha ornamental ocorre igualmente ${ }^{39}$, sendo um motivo que nos surge documentado desde época tardo-republicana/augustana, prolongando-se até ao séc. III ${ }^{40}$. A maior concentração de exemplares corresponde, sem dúvida, à época júlio-cláudia.

O fuso central é simples, sendo representado por uma moldura delimitada por sulcos realizados em duplo bisel.

Estas cronologias apontam-nos, assim, para uma época em que perduram os motivos tradicionais e mais clássicos do léxico decorativo romano. No entanto, o desenho dos mesmos bem como a organicidade naturalista que lhe deu origem encontram-se já afastados, sendo os motivos reelaborados e plasmados de forma mais volumosa. Os efeitos de sombra e luz, a alternância de volumes e o uso do trépano indicam-nos cronologias distintas da época de Augusto e dos inícios dos júlio-cláudios, quande a lineariedade e os efeitos plásticos, mais desenhados que esculpidos, pautavam a decoração.

Esta peça não nos surge isolada em termos de composição. Ainda que seja extremamente difícil encontrar paralelos no Império Romano, o territorium olisiponense oferece-nos outros capeamentos de ara com decorações precisamente iguais. Contam-se, assim, fragmentos de base de capeamento em Manique (Alcabideche), peça que fora classificada como imposta e datada de época visigótica ${ }^{41}$. Pensamos que, de facto, se tratará de um fragmento de capeamento ${ }^{42}$, como já referimos, e que a decoração - ainda que, à primeira vista, nos faça lembrar a estilização desse período - não pode ser confundida com aqueles motivos circulares que em época visigótica nos surgem vulgarmente.

38 Vide BINGÖL, "Das Ionische Normalkapitelle in Hellenistischer und Römischer Zeit in Kleinasien", AM, Supl. 20, 1980, pp. 84 e ss.

39 Gutierrez Behemerid, Ma Angeles, "Capiteles Romanos de la Peninsula Iberica”, Studia Archaeologica, 81, Valladolid, 1992, pp. 50 e ss.

40 G. BEHEMERID, ob. cit., n.os 69, 72, 84-90, 101, 102, 107 e 110.

41 Cardoso, Guilherme, Carta Arqueológica do Concelho de Cascais, ed. Câmara Municipal de Cascais, Vila Real de St. ${ }^{\circ}$ António, 1991, p. 37, n. ${ }^{\circ} 26$, fig. 6.

42 Em 1994, José d'Encarnaçâo afirma já que essa peça poderá corresponder a “...uma parte de um capitel de cipo ou ara. Resta, ainda que não muito perceptivel, a decoração em forma de corda donde pendem as folhas de acanto geometricamente estilizadas": EnCARnaÇão, J. d', Roteiro Epigráfico Romano de Cascais, ed. C.M.C., 1994, p. 68 , fig. 31 . 
Uma outra peça, proveniente de Areia, freguesia de Cascais e encontrada em inícios deste século por Félix Alves Pereira ${ }^{43}$, apresentamos uma decoração muito semelhante. Somente se conserva a base do capeamento e, aqui, a decoração é mais repetitiva e estilizada, sem que existam variações de motivo para motivo. Uma moldura sogueada, ainda conservada, estabelece a ligação entre a base e a parte superior do monumento. Proveniente da Ericeira, um outro fragmento se pode aproximar ${ }^{44}$.

Um conjunto distinto, extremamente importante - pelo número de exemplares, sua concentração geográfica e qualidade técnica - surgemos na região de Odrinhas. De alguns, quase poderíamos dizer estarmos perante cópias da que analisamos.

Temos, assim, um capeamento de ara de Faião ${ }^{45}$, com as mesmas características decorativas, quer nos dois registos, quer nas faces laterais e frontais que encontramos na peça de Lisboa. As diferenças reduzem-se a questões de pormenor, essencialmente no que respeita ao tipo de realização das rosetas centrais ou à possível inclusão de novos motivos, como acontece no exemplar de Faião, onde se inclui, tal como naquele de Cascais, uma moldura sogueada a estabelecer a ligação entre os dois registos. Outras duas peças são muito similares, sendo provenientes, igualmente, do Faião ${ }^{46}$.

43 Peça depositada no Museu da Associação dos Arqueólogos Portugueses, em Lisboa. Vários autores se lhe referem, entre os quais: AlmeIDA, C. A. Ferreira de, História da Arte em Portugal - Arte da Alta Idade Média, voi. 2, Ed. Alfa, Lisboa, 1986, p. 68 (figura). Refere o autor que a peça terá vindo de Odrinhas e que corresponderá a uma imposta, colocando a hipótese de “... ser um elo entre estes [testemunhos tardirromanos da mesma localidade] e a tão original arte da época visigòtica da área de Lisboa"; ENCARNAÇÃO, ob. cit., pp. 68 e 69, fig. 32; CARDOSO, ob. cit., p. 51, n. ${ }^{\circ} 60$, que atribui o nome de "frontal romano" à peça. Ainda lhe faz referência Mattoso, José, História de Portugal, vol. 1, Editorial Estampa, 1993, p. 350.

44 Gandra, Manuel J.; CAetano, Amélia, "Subsídios para a Carta Arqueológica do Concelho de Mafra", Boletim Cultural '94", Ed. C.M.M., 1995, p. 265. Peça encontrada na Rua Eduardo Burnay, da qual somente se conserva uma parte do registo inferior (base).

45 Peça depositada no Museu Regional de Odrinhas, N. ${ }^{\circ}$ Inv. F/LR/80/2: ALMEIDA, ob. cit., voi. 2, p. 24 (figura e respectiva legenda). Mais uma vez, o autor aponta uma cronologia tardia para este tipo de peças: provavelmente de época "tardirromana".

46 N.os de Inv. - F/LR/55/1; F/LR/55/2. 
Por último, um capeamento, quase completo, proveniente da Póvoa de Santo Adrião (Loures) ${ }^{47}$, oferece-nos quase um decalque da peça da Casa dos Bicos. Luís de Matos, que recentemente a publica, refere correctamente, a nosso ver, que "apesar das semelhanças com elementos iconográficos correntes na iconografia paleo-cristã, a tipologia do altar e os elementos escultóricos nele presentes apontam globalmente para datações mais antigas que aquelas que têm sido atribuídas a peças semelhantes"48.

Apesar de as estas semelhanças, nenhum destes elementos nos pode fornecer, em termos cronológicos, grandes informações. Assim, mais uma vez, restringimo-nos às análises comparativas e às características evidenciadas pelo exemplar, quanto ao tipo de talhe, léxico decorativo e efeito plástico.

Pelas considerações expostas, datamos este exemplar do séc. II.

3 - BASE (Fig. 6)

N. ${ }^{\circ}$ Inv. - 514 (Inv. Geral:5504)

\section{Descrição}

Matéria - mármore.

Técnica - vestígios de escopro de bisel no interior da escocia. Abrasivos de polimento em toda a superfície. A parte superior da peça - local de assentamento do fuste - apresenta um bujardado grosseiro realizado com escopro de ponta.

Dimensões (em cm) - altura - 25,5; altura do plinto - 9; dimensões do plinto - 58X58: diâmetro da base de assentamento do fuste - 25,5. Estado de conservação - Bom. Partido nos ângulos do plinto.

47 Matos, José Luís de, (Coord.), Inventário do Museu Nacional de Arqueologia

- Colecção de Escultura Romana, Ed. I.P.C.M./I.P.M., Lisboa, 1995, pp. 120 e 121.

48 Ibidem, p. 120. No entanto, o autor não especifica a cronologia da peça. Por outro lado, a descrição que apresenta parece-nos, em alguns casos, menos correcta, concretamente ao referir as rosetas centrais como "flores de seis pétalas" quando elas são três e muito semelhantes às do capeamento da Casa dos Bicos (apresentando-se aqui com quatro pétalas). A confusão advém, pensamos, do facto de, tal como no nosso exemplar, as terminações lobulares apresentarem dois sulcos a imitar o reviramento da folha, efeito de cariz naturalista que é sublinhado por pontos de trépano. O facto de a peça não apresentar, como refere o autor, "fastígios ou frontões" deve-se exclusivamente ao mau estado de conservação da palmeta central. 


\section{Análise descritiva}

Base composta por um plinto liso, a que se sobrepõe um toro semi-circular, cujo diâmetro máximo é coincidente com os lados do plinto. Por cima deste, uma pequena moldura de perfil recto estabelece a ligação a uma escocia reentrante. Esta é sobreposta por nova moldura, também de perfil recto, mas mais alta que a anterior, e cujo perfil de ligação à escocia é algo biselado. A terminar a peça, na sua parte superior, um novo toro circular, que se posiciona de forma reentrante em relação à dimensão máxima do plinto.

\section{Análise comparativa}

Em termos morfológicos, esta peça aproxima-se das bases jónica e ática, tal como são definidas por Vitruvio quanto aos seus elementos constituintes. Temos, assim, dois toros e uma escocia entre aqueles, para além do plinto que suporta a composição.

Apesar da semelhança morfológica, as dimensões destes elementos distanciam-se das prescritas por Vitruvio ${ }^{49}$.

Afastando-se da base toscana, pela simplicidade e especificidade desta, a base da Casa dos Bicos poderá ser aproximada ou da base jónica ou da corintia, ainda que existam diferenças - sobretudo quanto à inclusão de vários filetes nestas duas bases - que a impedem de ser classificada como tal ${ }^{50}$.

Inequivocamente de época romana, constitui uma reelaboração provincial, que segue, até certo ponto, a tipologia das bases empregues no Centro do Império, ilustrando uma inclusão dos elementos constituintes perfeitamente definidos. O resultado é, não obstante, um produto local que altera as proporções e as adequa ao monumento a erigir. Bastará compararmos este exemplar com as bases que encontramos noutras províncias, por exemplo na Gália, para detectamos paralelos próximos $^{51}$. A multiplicidade de bases gaulesas obriga a aceitar a ideia

49 GRANGER, Frank, (Trad.) Vitruvius on Architecture, Harvard University

Press, London, 1995, Book III, C. V (pp. 184-187).

50 Cf. Chitham, Robert, The Classical Orders of Architecture, Oxford, 1985, Plate 33.

51 BROISE, Pierre, "Éléments d'un ordre toscan provincial en Haute-Savoie", Gallia, tome XXVII, fase. 1, Paris, 1969, pp. 17-19. Os desenhos que o autor fornece 
de uma multiplicidade tipológica provincial, formada a partir de modelos pré-existentes, quadro que se poderia aceitar para a Lusitânia, ainda que os poucos vestígios até hoje documentados não nos permitam, para já, qualquer confirmação.

Esta base da Casa dos Bicos corresponde, assim, a um elemento de reelaboração das normas clássicas, mais do que a uma cópia das mesmas. A sua esmerada execução e o acabamento cuidado - com o recurso a abrasivos de polimento em toda a superfície - levam-nos a considerá-la como um produto de boa época, talvez do séc. II, apesar de já afastada dos preceitos mais rígidos de épocas anteriores ${ }^{52}$.

\section{4 - FRISOS e CAPEAMENTO VERTICAL (Fig. 7 a 9)}

4.1 (Fig. 7)

$N .^{\circ} \operatorname{Inv.~-~não~tem.~}$

Matéria - mármore róseo

Classificação - fragmento de friso

Dimensões (em cm) - altura conservada: 11,5; largura - 13,5; comprimento conservado: 10 .

4.2 (Fig. 8)

$N .^{\circ}$ Inv. - C.B $/ 206$

Matéria - mármore róseo

Classificação - fragmento de friso

Dimensões (em cm) - altura: 12; largura: 13,5; comprimento conservado: 20 .

\section{3 (Fig. 9)}

$N .^{\circ}$ Inv. -C.B $/ 232$

Matéria - mármore róseo

Classificação - fragmento de capeamento vertical

Dimensões (em cm) - espessura: 8; comprimento conservado: 27; profundidade da escocia: 2,5 .

correspondem às várias possibilidades de bases formadas a partir do modelo mais simples constituido com base na ordem toscana clássica.

52 A distinção em relação aos preceitos vitruvianos afasta-nos do séc. I. A reelaboração de modelos só pode ser realizada depois de um conhecimento prévio dos preceitos classicistas, conseguido inicialmente por materiais importados (conhecimento directo), ou por importação de mão-de-obra especializada. 


\section{Análise}

Estes três elementos não nos fornecem grandes informações.

O primeiro é uma moldura em gola directa, ou kyma lésbio, delimitada superiormente por quarto de círculo alargado de perfil convexo e por quarto de círculo alargado cóncavo na parte inferior.

Poderá corresponder a um pequeno friso de pedestal, ainda que integrado em entablamento de plinto. Este enquadramento arquitectónico é-nos sugerida pelas faces que se integrariam no edificio, concretamente duas paredes facetadas, com pequeno encaixe, que se encontra partido, no topo de uma delas.

O segundo elemento será um friso de cornija, apresentando um perfil menos projectado que o anterior mas muito semelhante morfologicamente. Face superior facetada, possuindo um pequeno elemento de encaixe (partido) que se integraria na parte superior do monumento a que se destinava. A face posterior não possui qualquer tratamento, pelo que pensamos deveria encostar à parede da construção.

O último fragmento constituirá, possivelmente, um capeamento de revestimento vertical, cujo perfil apresenta uma moldura convexa, em forma de quarto de círculo, delimitada superior e inferiormente por duas faixas salientes de perfil recto.

E-nos impossiível fazer qualquer correspondência cronológica destas peças. No entanto, o acabamento cuidado, o polimento da superfície e o tipo de perfil em presença, vulgar na decoração romana, são factores que nos levam a admitir estarmos em presença de elementos arquitectónicos de certa qualidade pertença, provavelmente, de um edifício de alguma importância, que utilizava ornamentos de bom acabamento tanto para a sua decoração como para o seu revestimento.

\section{CONCLUSÕES}

Este tipo de peças nunca mereceu, até aos nossos dias, algum comentário mais extenso, sobretudo no que diz respeito aos capeamentos de $\operatorname{ara}^{53}$. As referências que, ultimamente, têm sido feitas - ainda

53 Gostaríamos de salientar o facto de ter sido recentemente (1999) defendida uma tese de Mestrado dedicada exclusivamente a estas peças, na Faculdade de Ciências 
que importantes porquanto estabelecem uma distinção estilística em relação à decoração, similar no contorno, de época visigótica (com a qual, durante muito tempo, foram confundidas) - não vão muito mais longe quanto à sua contextualização ou quanto à tipologia decorativa.

Não será este, no entanto, o local para nos alongarmos em relação a um tema tão complexo. As observações que apresentámos permitem-nos, no entanto, e no que se refere mais directamente aos materiais analisados, estabelecer mais algumas considerações.

Em primeiro lugar, parece-nos indiscutível o facto de um tão grande número de capeamentos de ara 54 com tão evidentes similitudes fazerem parte de um mesmo centro produtor. Isto é, partimos do princípio de que, na sua origem, se pode delinear a existência de uma ou mais oficinas, ainda que, certamente, muito próximas entre si, as quais, em coordenadas espaço-temporais restritas, terão produzido este tipo de peças e abastecido, senão todo, grande parte do territorium Olisiponense.

As evidentes semelhanças estilísticas impelem-nos, com efeito, a colocarmos esta hipótese. Ainda que o estado de conservação de alguns dos capeamentos não nos permita uma visualização integral das peças, é possível detectamos constâncias. Na verdade, a morfologia, a composição ornamental, os motivos decorativos, o tipo de talhe, a matéria empregue, assim como a importância relativa de alguns dos elementos, concretamente das rosetas centrais, são algumas das características que podemos observar em, praticamente, todos eles.

Se compararmos as datações do capitel corintizante e do capeamento de ara, observaremos que a cronologia é similar, facto que nos leva a colocar a questão de as duas peças provirem da mesma oficina.

Pensamos que, no estado actual dos conhecimentos, será difícil concluir, linearmente, que a produção de todos os capeamentos e capitéis tenha tido por base uma mesma oficina. Pensamos, inclusivamente, que tal não terá ocorrido. Apesar das idênticas características, estilísticas e decorativas ${ }^{55}$, existem pormenores que levam a pensar estarmos perante centros produtores distintos, um para capeamentos e outro para

Sociais e Humanas da Universidade Nova de Lisboa: Carlos Vieira, Capitéis de ara do território de Olisipo.

54 Fazemos referência aos que citámos bibliograficamente.

55 As quais poderão ser explicadas, simplesmente, por semelhantes correntes estéticas. 
capitéis. O emprego intensivo dos abrasivos de polimento no capitel

- o qual, à partida, pelo local que ocuparia no conjunto do edificado, obstaria a tal tratamento da superfície - e a não constatação de tal expediente quanto ao capeamento de ara - o qual, pelo tipo de monumento que integraria, estaria muito mais próximo dos transeuntes - sugerem técnicas distintas de oficinas diferenciadas.

O tipo de pormenores que aparecem num e noutro elemento afiguram-se, também, totalmente distintos. Bastará, para tal, analisar as rosetas, para se optar por modelos distintos e diferentes mãos que participaram na sua realização.

Capeamento de ara e capitel provêm, em nossa opinião, de oficinas separadas, certamente especializadas na produção de cada um deste tipo de peças.

As terminações em círculo das hastes dos motivos laterais do capitel apontam, por outro lado, e na sequência da investigação que temos vindo a realizar, para "tiques de oficina", provavelmente especializadas em certos tipos de peças - no caso presente, os capitéis corintizantes - ainda que outros também aí pudessem ter sido produzidos.

Organizadas, certamente, com base na permanência de um mestre - que ditaria a composição decorativa dos espécimes podendoo mesmo executar alguns dos motivos, como será o caso das rosetas centrais -, a mão-de-obra seria indígena ou, em termos gerais, menos qualificada.

Se o quadro é delineável para a produção dos capeamentos de ara, pode, de igual modo, ser aplicado quanto aos capitéis. No capitel corintizante da Casa dos Bicos, é nítida a existência de cartões importados, o que pode ser observado na junção imperfeita da palmeta central, ou folha corintizante, às angulares.

As considerações expostas não obstam a que consideremos estes elementos como produtos de qualidade, provenientes de oficinas que operariam ou em Olisipo - onde as encomendas poderiam ser em maior número - ou junto às pedreiras donde era extraída a matéria-prima, durante a primeira metade do séc. II.

Essa qualidade é sublinhada pelas restantes peças - base e frisos - talvez da mesma época, que, embora que perfeitamente integrados nas correntes estéticas de então, denotam um certo afastamento dos cânones clássicos, facto que pode ser explicado por uma reelaboração provincial dos modelos tidos por base. 


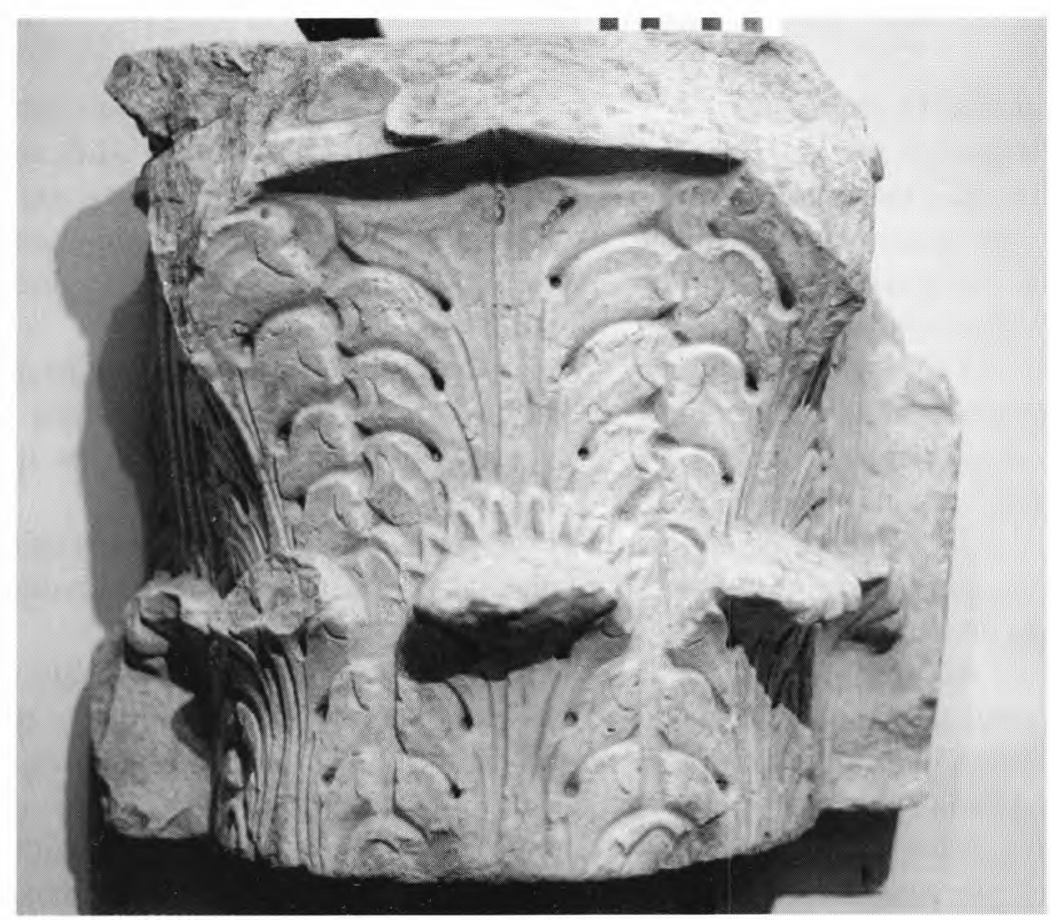

FIG. 1 - Capitel corintizante. Face frontal.

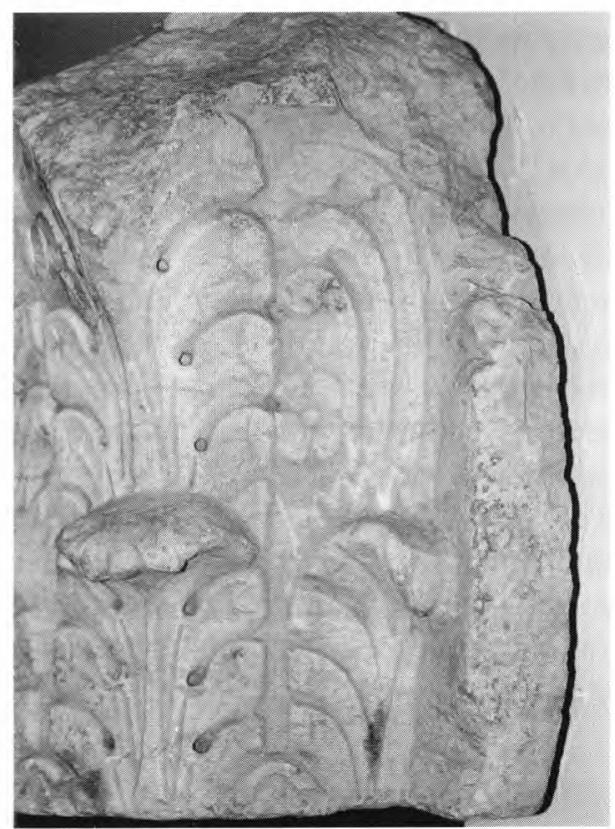

FIG. 2 - Capitel corintizante. Pormenor da face lateral. 


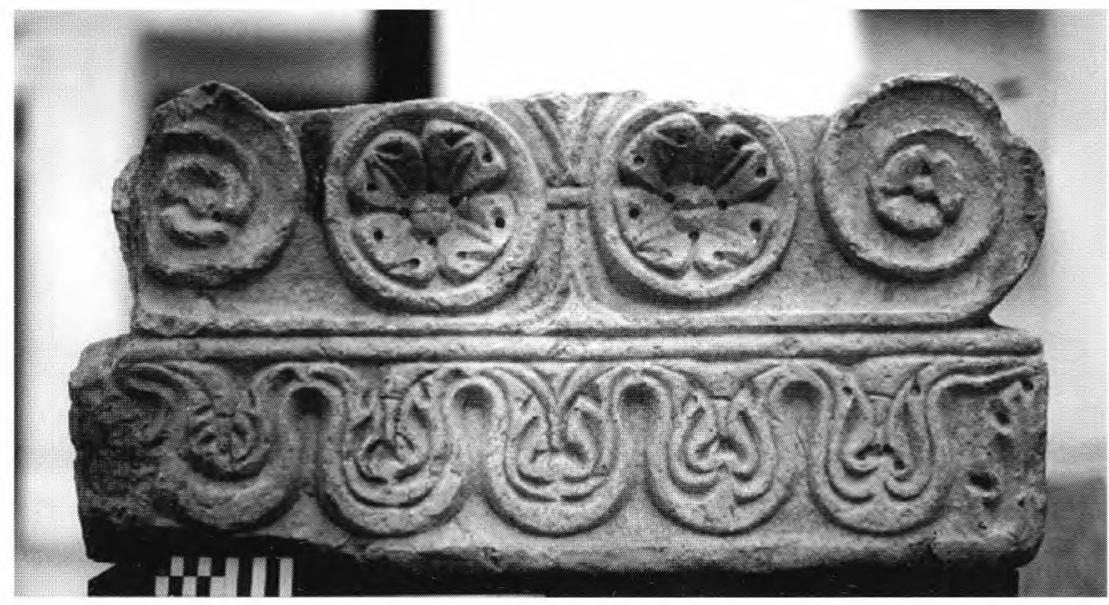

FIG. 3 - Capeamento de ara. Face frontal.

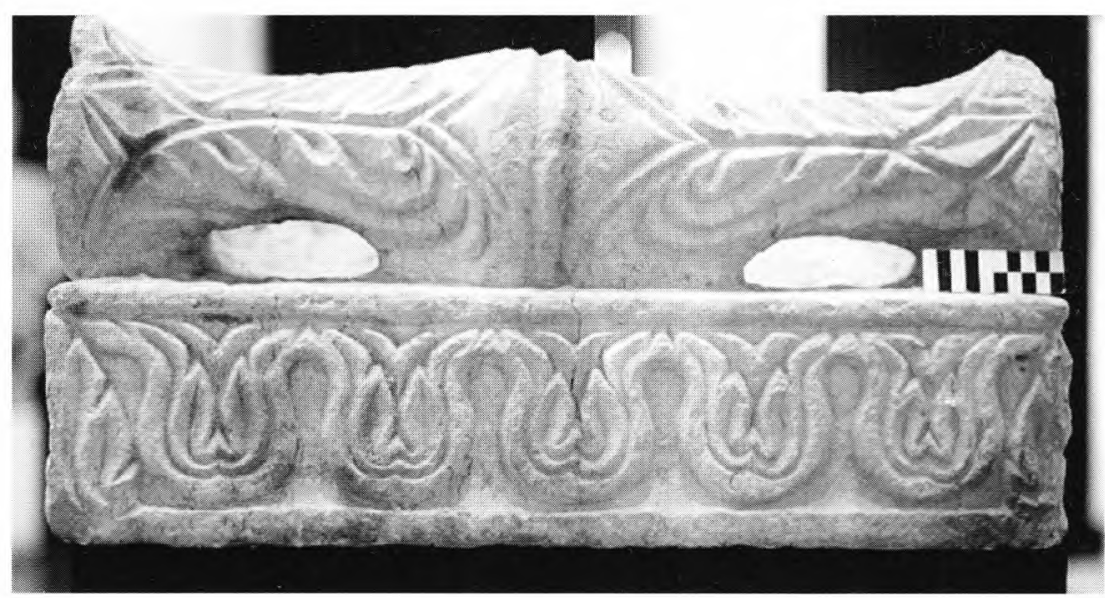

FIG. 4 - Roseta central da face frontal do capeamento de ara. 


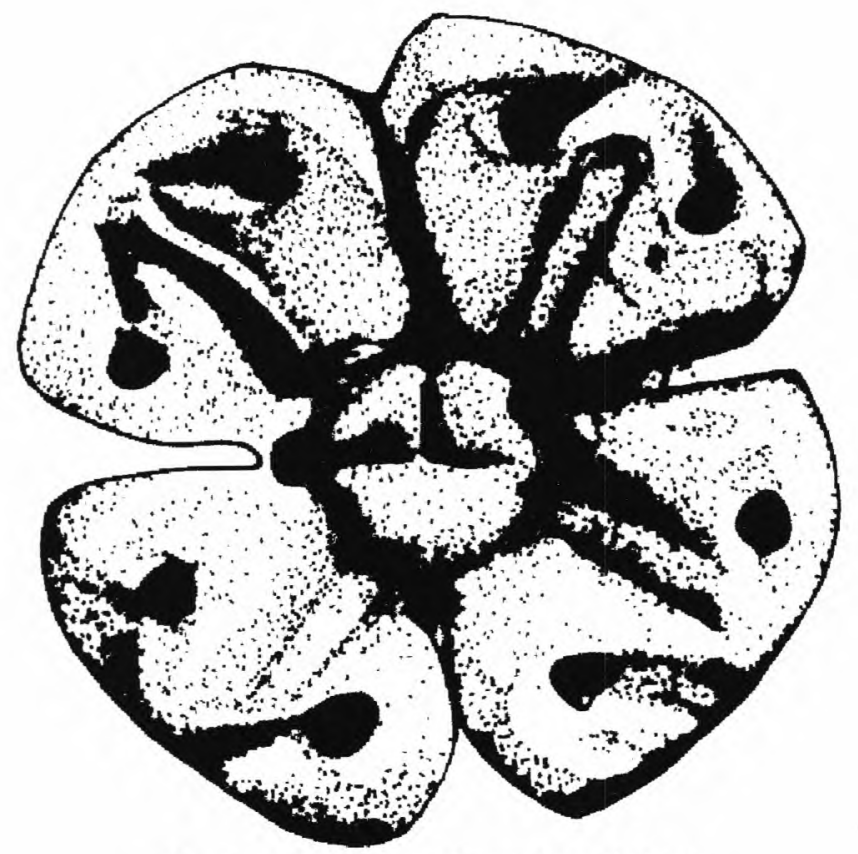

Fig. 5 - Capeamento de ara. Face lateral

(zona correspondente ao puluinus ou balaústre).

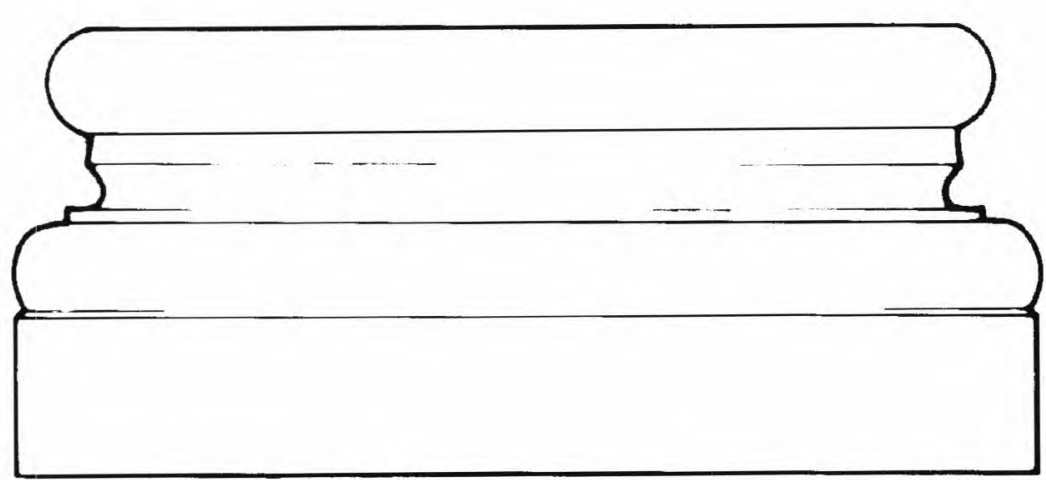

FIG. 6-Base.

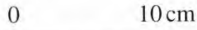




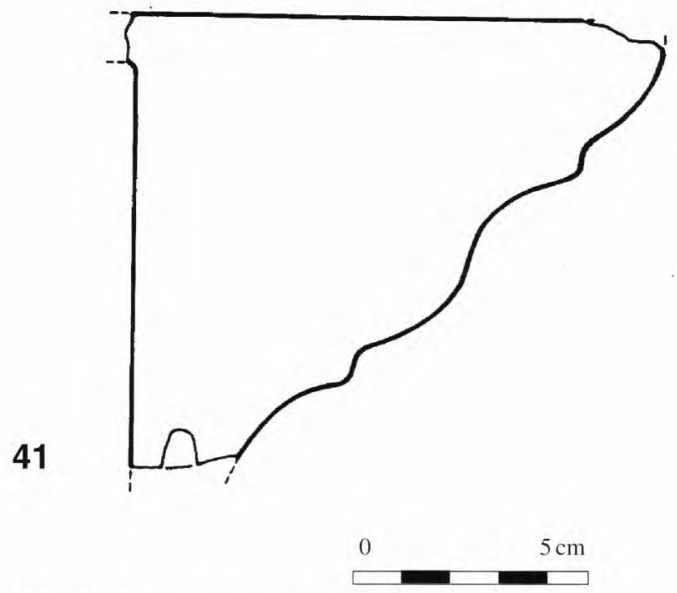

FIG. 7 - Fragmento de friso.

FIG. 8 - Fragmento de friso.
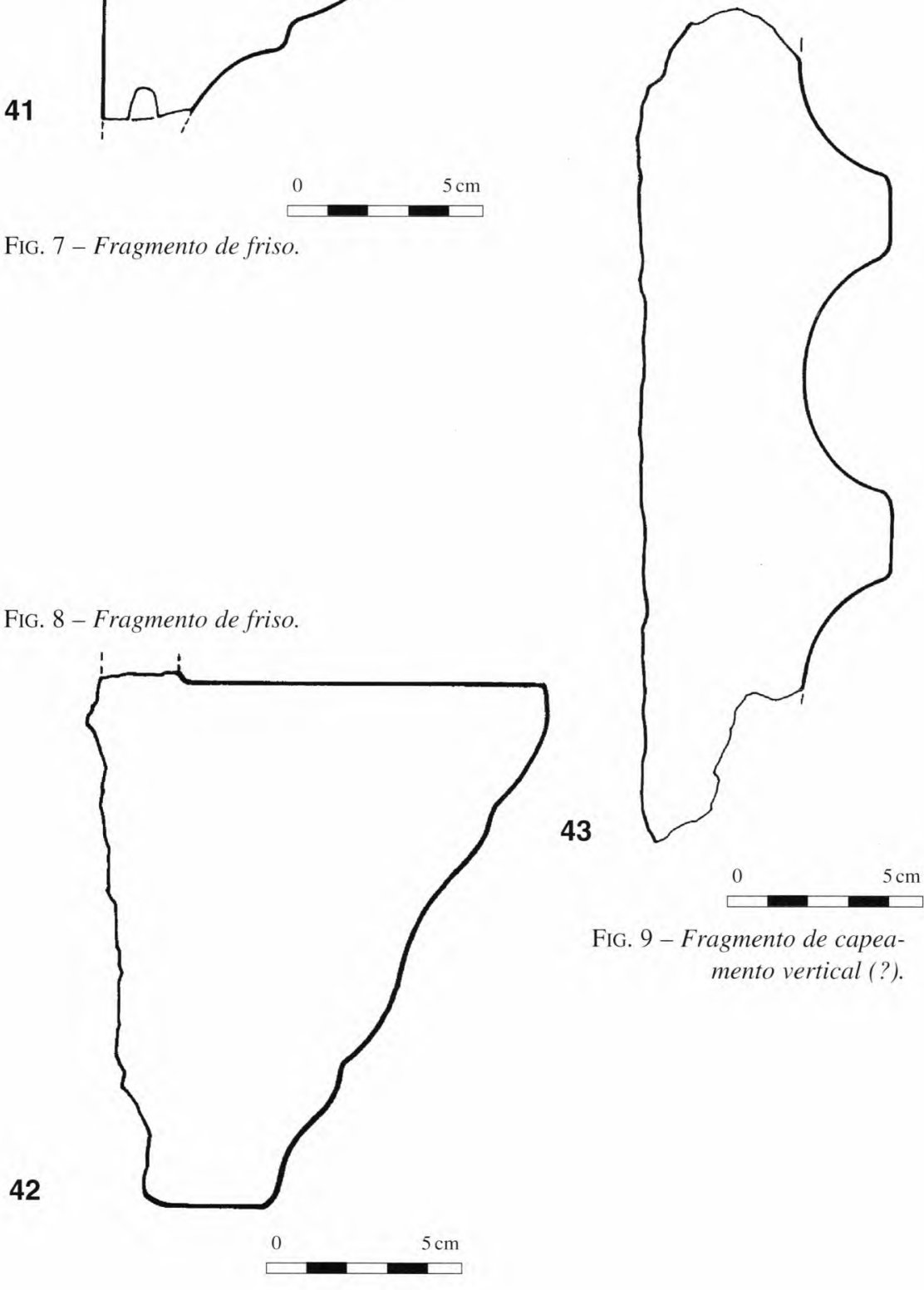

FIG. 9 - Fragmento de capeamento vertical (?). 